\title{
MEK inhibitors cobimetinib and trametinib, regressed a gemcitabine-resistant pancreatic-cancer patient-derived orthotopic xenograft (PDOX)
}

\author{
Kei Kawaguchi ${ }^{1,2,3}$, Kentaro Igarashi ${ }^{1,2}$, Takashi Murakami1,2, Tasuku Kiyuna ${ }^{1,2}$, \\ Thinzar M. Lwin'2, Ho Kyoung Hwang ${ }^{1,2}$, Jonathan C. Delong², Bryan M. Clary ${ }^{2}$, \\ Michael Bouvet ${ }^{2}$, Michiaki Unno ${ }^{3}$ and Robert M. Hoffman ${ }^{1,2}$ \\ ${ }^{1}$ AntiCancer, Inc., San Diego, CA, USA \\ ${ }^{2}$ Department of Surgery, University of California, San Diego, CA, USA \\ ${ }^{3}$ Department of Surgery, Graduate School of Medicine, Tohoku University, Sendai, Japan \\ Correspondence to: Robert M. Hoffman, email: all @anticancer.com \\ Michael Bouvet, email: mbouvet@ucsd.edu \\ Bryan M. Clary, email: bclary@ucsd.edu
}

Keywords: pancreatic cancer, PDOX, nude mice, orthotopic, drug-response

Received: April 15, 2017

Accepted: April 20, 2017

Published: May 07, 2017

Copyright: Kawaguchi et al. This is an open-access article distributed under the terms of the Creative Commons Attribution License 3.0 (CC BY 3.0), which permits unrestricted use, distribution, and reproduction in any medium, provided the original author and source are credited.

\section{ABSTRACT}

A pancreatic ductal adenocarcinoma (PDAC), obtained from a patient, was grown orthotopically in the pancreatic tail of nude mice to establish a patient-derived orthotopic (PDOX) model. Seven weeks after implantation, PDOX nude mice were divided into the following groups: untreated control $(n=7)$; gemcitabine $(100 \mathrm{mg} / \mathrm{kg}$, i.p., once a week for 2 weeks, $n=7$ ); cobimetinib ( $5 \mathrm{mg} / \mathrm{kg}$, p.0., 14 consecutive days, $n=7$ ); trametinib $(0.3 \mathrm{mg} / \mathrm{kg}$, p.o., 14 consecutive days, $n=7)$; trabectedin $(0.15 \mathrm{mg} / \mathbf{k g}$, i.v., once a week for 2 weeks, $n=7$ ); temozolomide ( $25 \mathrm{mg} / \mathrm{kg}$, p.o., 14 consecutive days, $n=7$ ); carfilzomib ( $2 \mathrm{mg} / \mathrm{kg}$, i.v., twice a week for 2 weeks, $n=7)$; bortezomib $(1 \mathrm{mg} / \mathrm{kg}$, i.v., twice a week for 2 weeks, $n=7)$; MK-1775 (20 mg/ kg, p.0., 14 consecutive days, $n=7)$; BEZ-235 (45 mg/ kg, p.o., 14 consecutive days, $n=7)$; vorinostat $(50 \mathrm{mg} / \mathrm{kg}$, i.p., 14 consecutive days, $n=7$ ). Only the MEK inhibitors, cobimetinib and trametinib, regressed tumor growth, and they were more significantly effective than other therapies $(p<0.0001$, respectively), thereby demonstrating the precision of the PDOX models of PDAC and its potential for individualizing pancreatic-cancer therapy.

\section{INTRODUCTION}

Gemcitabine (GEM) is first-line therapy for pancreatic cancer $[1,2]$ with a poor response rate of approximately $10 \%$ [3]. Novel drugs tested on pancreatic cancer include MEK inhibitors (cobimetinib [COB], trametinib [TRA]) [5-8], an PI3K/mTOR inhibitor (BEZ-235) [4-9], an HDAC inhibitor (vorinostat) [10], proteasome inhibitors (bortezomib, carfilzomib) [11, 12], a Wee-1 inhibitor (MK-1775) [13], temozolomide (TEM) [14] and trabectedin (TRAB) [15-17]. Whether a patient's tumor is sensitive to any of these drugs is not knowable a priory. Genetic profiling can provide important information, but does not necessarily match drug sensitivity [18].
Clinically-relevant mouse models of pancreatic cancer could enable precision therapy based on the individual patient tumor. For this purpose, our laboratory pioneered the patient-derived orthotopic xenograft (PDOX) nude-mouse model with the technique of surgical orthotopic implantation (SOI), including breast cancer [19], ovarian cancer [20], lung cancer [21], cervical cancer [22], colon cancer [23-25], stomach cancer [26], melanoma [18, 27-29], sarcoma [30-34], as well as pancreatic cancer [35-38]. The PDOX model, developed by our laboratory over the past 28 years, has many advantages, including a patient-like metastatic pattern, over subcutaneous-transplant models which are growing ectopically under the skin and very rarely metastasize [39]. 
In a previous PDOX study of a BRAF-V600Emutant melanoma, TRA, an MEK inhibitor, was the only agent of the 4 tested that caused tumor regression. Another MEK inhibitor, $\mathrm{COB}$, could slow but not arrest growth or cause regression of the melanoma. The patient in this study had a BRAF-V600E-mutant melanoma and would be considered to be a strong candidate for vemurafenib (VEM) as first-line therapy, since VEM targets this mutation. However, VEM was not effectivein the PDOX model. The PDOX model thus helped identify the veryhigh efficacy of TRA against the melanoma PDOX and is a promising drug for this patient. These results demonstrated the powerful precision of the PDOX model for cancer therapy, not achievable by genomic analysis alone [18].

Therefore, in the present study, in a PDOX nudemouse model with pancreatic cancer from a patient we evaluated TRA and COB and 8 other drugs to find the best treatment strategy for this patient and demonstrate the precision of the pancreatic-cancer PDOX model. As with the melanoma PDOX, TRA and COB were most effective in the pancreatic cancer PDOX.

\section{RESULTS AND DISCUSSION}

All tested drugs, including GEM, COB, TRA, TRAB, TEM, carfilzomib, bortezomib, BEZ-235, vorinostat, inhibited tumor growth in the pancreatic cancer PDOX compared to untreated control ( $p<0.0001$, respectively) on day 14 after treatment initiation. However, only the MEK inhibitors, COB and TRA, regressed tumor growth and they were significantly more effective than other drugs ( $p<0.0001$, respectively) including GEM that is widely used as first line standard therapy for pancreatic cancer $(p<0.0001)$. There was no significant difference between COB and TRA ( $p=0.0988$ ) (Figures 1,2$)$.

The relative body weight on day 14 compared with day 0 did not significantly differ between any treatment group or untreated control (Figure 3). There were no animal deaths in any groups.

Histologically, the untreated control tumor was mainly comprised of viable cells, in contrast, necrosis was observed in the tumor treated with COB (Figure 4).

GEM is first-line therapy for pancreatic cancer, but the response rate is only approximately $10 \%$ [3]. In the present study, GEM could not arrest or regress the tumor growth but showed inhibition compared to the untreated control. In contrast, $\mathrm{COB}$ and TRA regressed the tumor and were significantly more effective than GEM. These results suggest that MEK inhibitors might be used as first line therapy for this patient.

Although, the present patient's tumor was sensitive to MEK inhibitors in the PDOX models. Other patients' tumors may be sensitive for other drugs such as TRAB, TEM, carfilzomib, bortezomib, MK-1775, BEZ-235, or vorinostat, as well as GEM. A PDOX model enables precise, individualized therapy, especially for recalcitrant disease such as pancreatic cancer [18].

Previously-developed concepts and strategies of highly-selective tumor targeting can take advantage of molecular targeting of tumors, including tissue-selective therapy which focuses on unique differences between normal and tumor tissues [40-45].

\section{MATERIALS AND METHODS}

\section{Mice}

Athymic $n u / n u$ nude mice (AntiCancer Inc., San Diego, CA), 4-6 weeks old, were used in this study. Animals were housed in a barrier facility on a high efficacy particulate arrestance (HEPA)-filtered rack under standard conditions of 12-hour light/dark cycles. The animals were fed an autoclaved laboratory rodent diet. All mouse surgical procedures and imaging were performed with the animals anesthetized by subcutaneous injection of a ketamine mixture $(0.02 \mathrm{ml}$ solution of $20 \mathrm{mg} / \mathrm{kg}$ ketamine, $15.2 \mathrm{mg} /$ $\mathrm{kg}$ xylazine, and $0.48 \mathrm{mg} / \mathrm{kg}$ acepromazine maleate). The response of animals during surgery was monitored to ensure adequate depth of anesthesia. The animals were observed on a daily basis and humanely sacrificed by $\mathrm{CO}_{2}$ inhalation if they met the following humane endpoint criteria: severe tumor burden (more than $20 \mathrm{~mm}$ in diameter), prostration, significant body weight loss, difficulty breathing, rotational motion, and body temperature drop. All animal studies were conducted in accordance with the principles and procedures outlined in the National Institutes of Health Guide for the Care and Use of Animals under Assurance Number A3873-1 [18, 27-29].

\section{Patient-derived tumor}

The pancreatic cancer was resected in the Department of Surgery, University of California, San Diego (UCSD). Written informed consent was provided by the patient, and the Institutional Review Board (IRB) of UCSD approved this experiment.

\section{Establishment of PDOX models of pancreatic cancer by surgical orthotopic implantation (SOI)}

A fresh sample of pancreatic cancer of the patient was obtained and transported immediately to the laboratory at AntiCancer, Inc., on wet ice. The sample was cut into 5-mm fragments and implanted subcutaneously in nude mice. After five weeks, the subcutaneously-implanted tumors grew to more than $10 \mathrm{~mm}$ in diameter. The subcutaneously-grown tumors were then harvested and cut into small fragments $\left(3 \mathrm{~mm}^{3}\right)$. After nude mice were anesthetized with the ketamine solution described above, a 1-2 cm skin incision was made on the left side abdomen through the skin, fascia and peritoneum and pancreas was 
exposed. Surgical sutures ( $8-0$ nylon) were used to implant tumor fragments onto the tail of pancreas to establish the PDOX model [35-38]. The wound was closed with a 6-0 nylon suture (Ethilon, Ethicon, Inc., NJ, USA.

\section{Treatment study design}

PDOX mouse models were randomized into the following groups of 7 mice each: untreated control $(n=7)$;
GEM (100 mg/kg, i.p., once a week for 2 weeks, $n=7)$; COB (5 mg/kg, p.o., 14 consecutive days, $n=7$ ); TRA (0.3 mg/kg, p.o., 14 consecutive days, $n=7)$; TRAB $(0.15 \mathrm{mg} / \mathrm{kg}$, i.v., once a week for 2 weeks, $n=7)$; TEM (25 mg/kg, p.o., 14 consecutive days, $n=7$ ); carfilzomib ( $2 \mathrm{mg} / \mathrm{kg}$, i.v., twice a week for 2 weeks, $n=7$ ); bortezomib $(1 \mathrm{mg} / \mathrm{kg}$, i.v., twice a week for 2 weeks, $n=7)$; MK-1775 (20 mg/kg, p.o., 14 consecutive days, $n=7$ ); BEZ-235 (45 mg/kg, p.o., 14 consecutive days, $n=7$ ); vorinostat
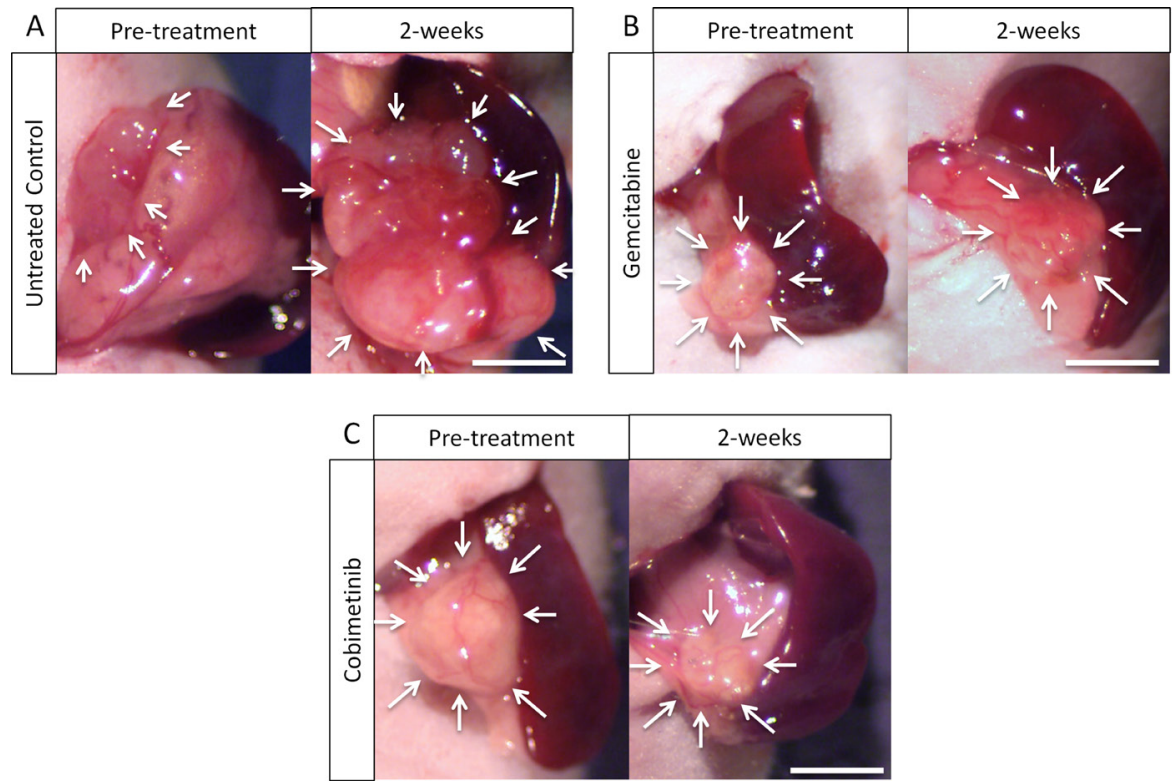

Figure 1: Macroscopic evaluation of therapeutic efficacy. (A) Control. (B) Tumor treated with gemcitabine (GEM). (C) Treatment with cobimetinib (COB). White arrows show PDOX tumors on the pancreas. Scale bars: $5 \mathrm{~mm}$.

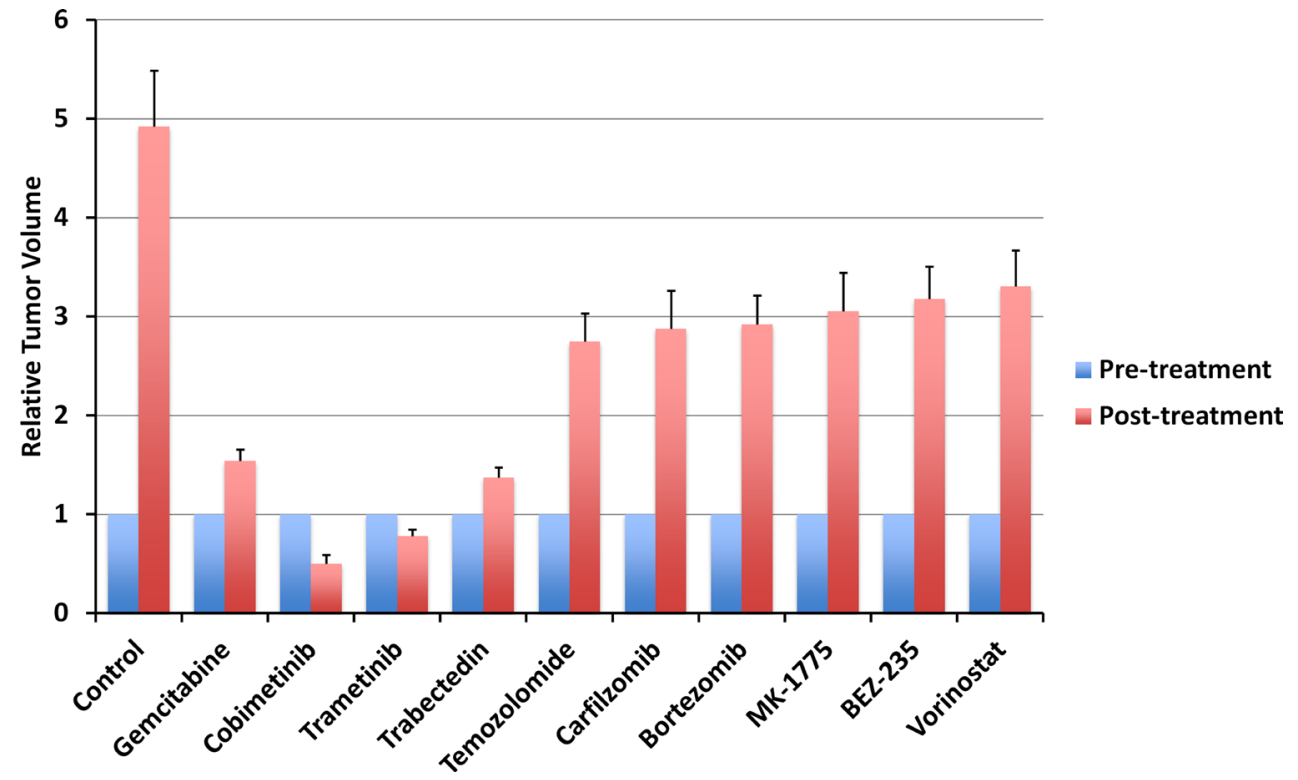

Figure 2: Quantitative treatment efficacy of 10 drugs. Line graph shows relative tumor volume at post-treatment relative to pre-treatment tumor volume. All treatments significantly inhibited tumor growth compared to untreated control $(p<0.0001)$. Only MEK inhibitors (COB, TRA) regressed tumor growth. Error bars: \pm SD. 
(50 mg/kg, i.p., 14 consecutive days, $n=7$ ). Tumor length and width were measured both pre- and post-treatment. Tumor volume was calculated with the following formula: Tumor volume $\left(\mathrm{mm}^{3}\right)=$ length $(\mathrm{mm}) \times$ width $(\mathrm{mm}) \times$ width $(\mathrm{mm}) \times 1 / 2$. Data are presented as mean $\pm \mathrm{SD}$. The tumor volume ratio is defined at the tumor volume at a posttreatment point relative to pre-treatment tumor volume.

\section{Imaging of the pancreatic cancer PDOX model}

Imaging of the macroscopic tumor was performed with the OV100 Small Animal Imaging System (Olympus, Tokyo, Japan).

\section{Histological examination}

Fresh tumor samples were fixed in $10 \%$ formalin and embedded in paraffin before sectioning and staining. Tissue sections $(5 \mu \mathrm{m})$ were deparaffinized in xylene and rehydrated in an ethanol series. Hematoxylin and eosin (H\&E) staining was performed according to standard protocols. Histological examination was performed with a BHS System Microscope (Olympus Corporation, Tokyo, Japan). Images were acquired with INFINITY ANALYZE software (Lumenera Corporation, Ottawa, Canada) $[18,29]$.

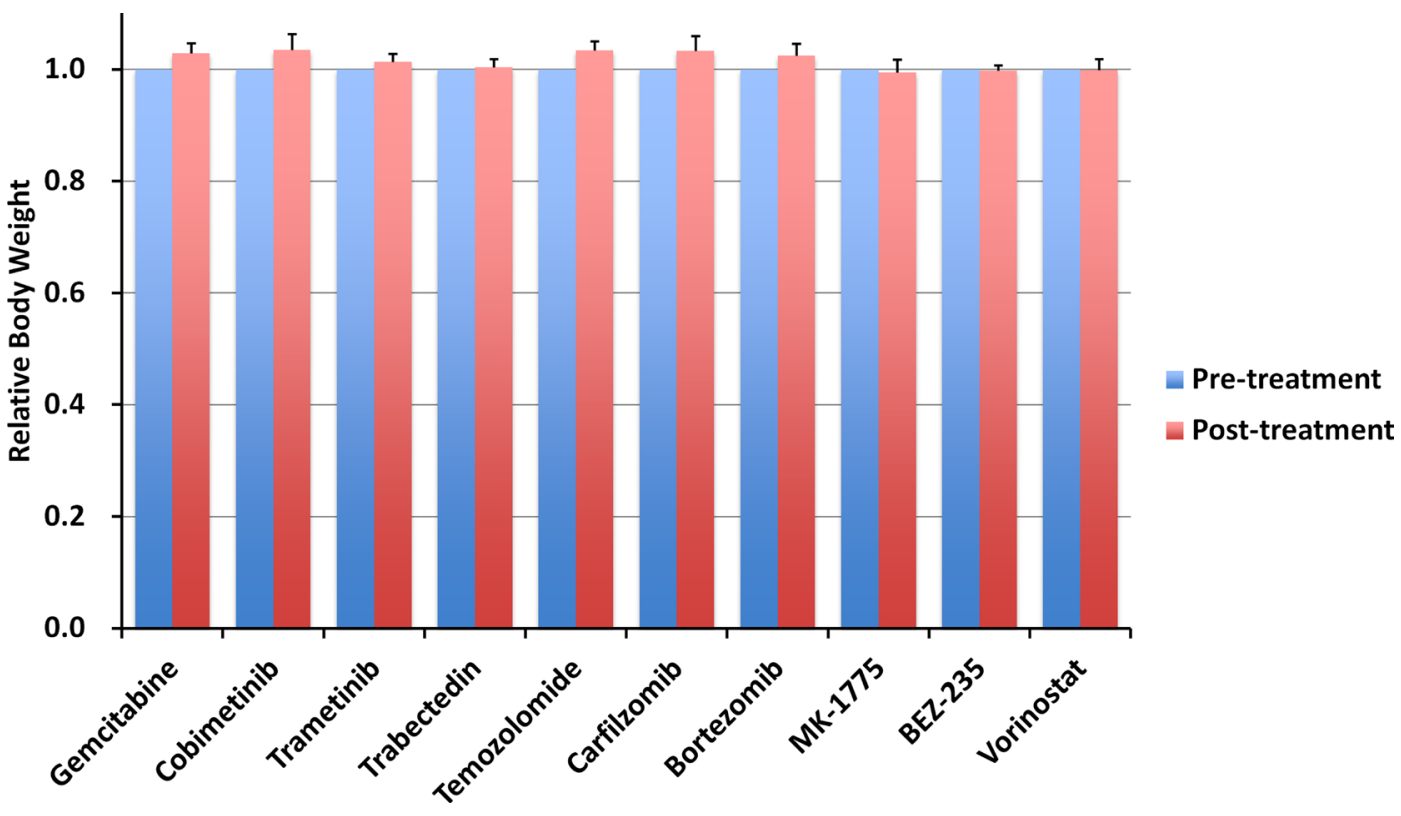

Figure 3: Effect of each drug on mouse body weight. Bar graph shows relative body weight in each treatment group at posttreatment relative to pre-treatment. Error bars: \pm SD.

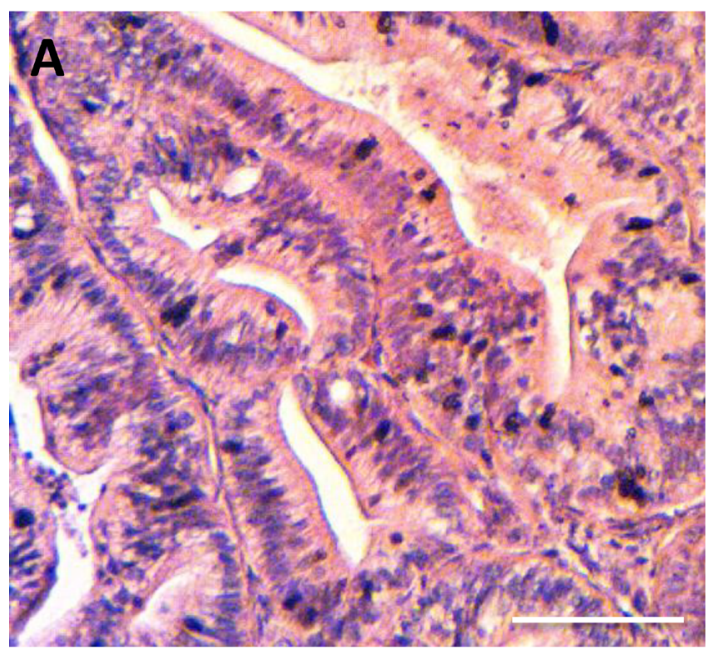

Untreated control

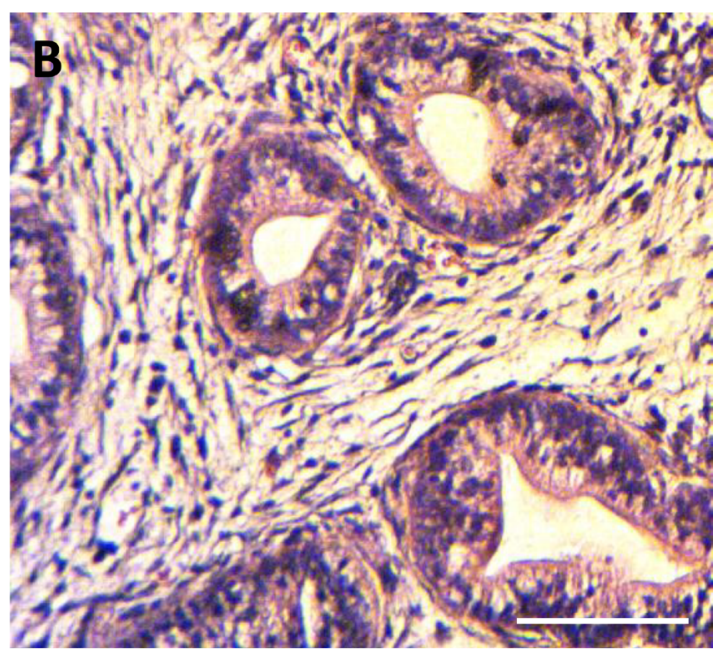

Cobimetinib

Figure 4: Tumor histology after treatment. (A) Untreated control. (B) Treated with COB. Scale bars: $100 \mu \mathrm{m}$ 


\section{Statistical analysis}

JMP version 11.0 was used for all statistical analyses. Significant differences for continuous variables were determined using the Mann-Whitney $U$ test. Line graphs express mean values and error bars show standard deviation (SD). A probability value of $P \leq 0.05$ was considered statistically significant.

\section{CONCLUSIONS}

In the present study, the PDOX model identified the ability of MEK inhibitors to regress a pancreatic cancer PDOX. That COB and TRA caused tumor regression indicated their potential efficacy for the patient donor of the PDOX in the present study. These results demonstrate the powerful precision of the PDOX model to distinguish the most effective of the 10 drugs tested.

Future experiments will test the present and other pancreatic cancer PDOX models with various therapies and compare the results with clinical outcome.

\section{CONFLICTS OF INTEREST}

None.

\section{REFERENCES}

1. Burris HA 3rd, Moore MJ, Andersen J, Green MR, Rothenberg ML, Modiano MR, Cripps MC, Portenoy RK, Storniolo AM, Tarassoff P, Nelson R, Dorr FA, Stephens $\mathrm{CD}$, Von Hoff DD. Improvements in survival and clinical benefit with gemcitabine as first-line therapy for patients with advanced pancreas cancer: a randomized trial. J Clin Oncol. 1997; 15:2403-2413.

2. Jenks S. AACR highlights: promise for treating pancreatic cancer. J Natl Cancer Inst. 2011; 103:786-787.

3. Conroy T, Desseigne F, Ychou M, Bouché O, Guimbaud R, Bécouarn Y, Adenis A, Raoul JL, Gourgou-Bourgade S, de la Fouchardière C, Bennouna J, Bachet JB, Khemissa-Akouz F, et al. FOLFIRINOX versus gemcitabine for metastatic pancreatic cancer. N Engl J Med. 2011; 364:1817-1825.

4. Alagesan B, Contino G, Guimaraes AR, Corcoran RB, Deshpande V, Wojtkiewicz GR, Hezel AF, Wong KK, Loda M, Weissleder R, Benes C, Engelman JA, Bardeesy N. Combined MEK and PI3K inhibition in a mouse model of pancreatic cancer. Clin Cancer Res. 2015; 21:396-404.

5. Junttila MR, Devasthali V, Cheng JH, Castillo J, Metcalfe C, Clermont AC, Otter DD, Chan E, Bou-Reslan H, Cao T, Forrest W, Nannini MA, French D, et al. Modeling targeted inhibition of MEK and PI3 kinase in human pancreatic cancer. Mol Cancer Ther. 2015; 14:40-47.

6. Li JR, Cheng CL, Yang CR, Ou YC, Wu MJ, Ko JL. Dual inhibitor of phosphoinositide 3-kinase/mammalian target of rapamycin NVP-BEZ235 effectively inhibits cisplatin- resistant urothelial cancer cell growth through autophagic flux. Toxicol Lett. 2013; 220:267-276.

7. Kim KW, Myers CJ, Jung DK, Lu B. NVP-BEZ-235 enhances radiosensitization via blockade of the PI3K/ mTOR pathway in cisplatin-resistant non-small cell lung carcinoma. GenesCancer. 2014; 5:293-302. doi: 10.18632/ genesandcancer.27.

8. Sharma N, Nanta R, Sharma J, Gunewardena S, Singh KP, Shankar S, Srivastava RK. PI3K/AKT/mTOR and sonic hedgehog pathways cooperate together to inhibit human pancreatic cancer stem cell characteristics and tumor growth. Oncotarget. 2015; 6:32039-32060. doi: 10.18632/ oncotarget.5055.

9. Wong MH, Xue A, Baxter RC, Pavlakis N, Smith RC. Upstream and Downstream Co-inhibition of Mitogen-Activated Protein Kinase and PI3K/Akt/mTOR Pathways in Pancreatic Ductal Adenocarcinoma. Neoplasia. 2016; 18:425-435.

10. Kumagai T, Wakimoto N, Yin D, Gery S, Kawamata N, Takai N, Komatsu N, Chumakov A, Imai Y, Koeffler HP. Histone deacetylase inhibitor, suberoylanilide hydroxamic acid (Vorinostat, SAHA) profoundly inhibits the growth of human pancreatic cancer cells. Int J Cancer. 2007; 121:656-665.

11. McConkey DJ, Zhu K. Mechanisms of proteasome inhibitor action and resistance in cancer. Drug Resist Updat. 2008; 11:164-179.

12. Gong L, Yang B, Xu M, Cheng B, Tang X, Zheng P, Jing Y, Wu GJ. Bortezomib-induced apoptosis in cultured pancreatic cancer cells is associated with ceramide production. Cancer Chemother Pharmacol. 2014; 73:69-77.

13. Lal S, Zarei M, Chand SN, Dylgjeri E, MambelliLisboa NC, Pishvaian MJ, Yeo CJ, Winter JM, Brody JR. WEE1 inhibition in pancreatic cancer cells is dependent on DNA repair status in a context dependent manner. Sci Rep. 2016; 6:33323.

14. Gupta S, Sathishkumar S, Ahmed MM. Influence of cell cycle checkpoints and 533 function on the toxicity of temozolomide in human pancreatic cancer cells. Pancreatology. 2010; 10:565-579.

15. D'Incalci M, Zambelli A. Trabectedin for the treatment of breast cancer. Expert Opin Investig Drugs. 2016; 25:105-115.

16. Miao X, Koch G, Straubinger RM, Jusko WJ. Pharmacodynamic modeling of combined chemotherapeutic effects predicts synergistic activity of gemcitabine and trabectedin in pancreatic cancer cells. Cancer Chemother Pharmacol. 2016; 77:181-193.

17. Miao X, Koch G, Ait-Oudhia S, Straubinger RM, Jusko WJ. Pharmacodynamic Modeling of Cell Cycle Effects for Gemcitabine and Trabectedin Combinations in Pancreatic Cancer Cells. Front Pharmacol. 2016; 7:421.

18. Kawaguchi K, Murakami T, Chmielowski B, Igarashi K, Kiyuna T, Unno M, Nelson SD, Russell TA, Dry SM, Li Y, Eilber FC, Hoffman RM. Vemurafenib-resistant BRAFV600E-mutated melanoma is regressed by MEK-targeting drug trametinib, but not cobimetinib in a patient-derived 
orthotopic xenograft (PDOX) mouse model. Oncotarget. 2016; 7:71737-71743. doi: 10.18632/oncotarget.12328.

19. Fu X, Le P, Hoffman RM. A metastatic-orthotopic transplant nude-mouse model of human patient breast cancer. Anticancer Res. 1993; 13:901-904.

20. Fu X, Hoffman RM. Human ovarian carcinoma metastatic models constructed in nude mice by orthotopic transplantation of histologically-intact patient specimens. Anticancer Res. 1993; 13:283-286.

21. Wang X, Fu X, Hoffman RM. A new patient-like metastatic model of human lung cancer constructed orthotopically with intact tissue via thoracotomy in immunodeficient mice. Int J Cancer. 1992; 51:992-995.

22. Hiroshima Y, Zhang Y, Zhang M, Maawy A, Mii S, Yamamoto M, Uehara F, Miwa S, Yano S, Murakami T, Momiyama M, Chishima T, Tanaka K, et al. Establishment of a patient-derived orthotopic xenograph (PDOX) model of HER-2-positive cervical cancer expressing the clinical metastatic pattern. PLoS One. 2015; 10:e0117417.

23. Fu X, Besterman JM, Monosov A, Hoffman RM. Models of human metastatic colon cancer in nude mice orthotopically constructed by using histologically intact patient specimens. Proc Natl Acad Sci USA. 1991; 88:9345-9349.

24. Metildi CA, Kaushal S, Luiken GA, Talamini MA, Hoffman RM, Bouvet M. Fluorescently-labeled chimeric anti-CEA antibody improves detection and resection of human colon cancer in a patient-derived orthotopic xenograft (PDOX) nude mouse model. J Surg Oncol. 2014; 109:451-458.

25. Hiroshima Y, Maawy A, Metildi CA, Zhang Y, Uehara F, Miwa S, Yano S, Sato S, Murakami T, Momiyama M, Chishima T, Tanaka K, Bouvet M, et al. Successful fluorescence-guided surgery on human colon cancer patient-derived orthotopic xenograft mouse models using a fluorophore-conjugated anti-CEA antibody and a portable imaging system. J Laparoendosc Adv Surg Tech A. 2014; 24:241-247.

26. Furukawa T, Kubota T, Watanabe M, Kitajima M, Fu X, Hoffman RM. Orthotopic transplantation of histologically intact clinical specimens of stomach cancer to nude mice: correlation of metastatic sites in mouse and individual patient donors. Int J Cancer. 1993; 53:608-612.

27. Yamamoto M, Zhao M, Hiroshima Y, Zhang Y, Shurell E, Eilber F,C, Bouvet M, Noda M, Hoffman RM. Efficacy of tumor-targeting Salmonella typhimurium A1-R on a melanoma patient-derived orthotopic xenograft (PDOX) nude-mouse model. PLoS One. 2016; 11:e0160882.

28. Kawaguchi K, Igarashi K, Murakami T, Chmielowski B, Kiyuna T, Zhao M, Zhang Y, Singh A, Unno M, Nelson SD, Russell TA, Dry SM, Li Y, et al. Tumor-targeting Salmonella typhimurium A1-R combined with temozolomide regresses malignant melanoma with a BRAF-V600E mutation in a patient-derived orthotopic xenograft (PDOX) model. Oncotarget. 2016; 7:85929-85936. doi: 10.18632/ oncotarget.13231.
29. Kawaguchi K, Igarashi K, Murakami T, Zhao M, Zhang Y, Chmielowski B, Kiyuna T, Nelson SD, Russell TA, Dry SM, Li Y, Unno M, Eilber F, et al. Tumor-targeting Salmonella typhimurium A1-R sensitizes melanoma with a BRAF-V600E mutation to vemurafenib in a patient-derived orthotopic xenograft (PDOX) nude mouse model. J Cell Biochem. 2017; 118:2314-2319. doi: 10.1002/jcb.25886.

30. Hiroshima Y, Zhang Y, Zhang N, Uehara F, Maawy A, Murakami T, Mii S, Yamamoto M, Miwa S, Yano S, Momiyama M, Mori R, Matsuyama R, et al. Patient-derived orthotopic xenograft (PDOX) nude mouse model of softtissue sarcoma more closely mimics the patient behavior in contrast to the subcutaneous ectopic model. Anticancer Res. 2015; 35:697-701.

31. Hiroshima Y, Zhao M, Zhang Y, Zhang N, Maawy A, Murakami T, Mii S, Uehara F, Yamamoto M, Miwa S, Yano S, Momiyama M, Mori R, et al. Tumor-targeting Salmonella typhimurium A1-R arrests a chemo-resistant patient soft-tissue sarcoma in nude mice. PLoS One. 2015; 10:e0134324.

32. Murakami T, DeLong J, Eilber FC, Zhao M, Zhang Y, Zhang N, Singh A, Russell T, Deng S, Reynoso J, Quan C, Hiroshima Y, Matsuyama R, et al. Tumor-targeting Salmonella typhimurium A1-R in combination with doxorubicin eradicate soft tissue sarcoma in a patientderived orthotopic xenograft PDOX model. Oncotarget. 2016; 7:12783-12790. doi: 10.18632/oncotarget.7226.

33. Kiyuna T, Murakami T, Tome Y, Kawaguchi K, Igarashi K, Zhang Y, Zhao M, Li Y, Bouvet M, Kanaya F, Singh A, Dry S, Eilber FC, et al. High efficacy of tumor-targeting Salmonella typhimurium A1-R on a doxorubicin- and dactolisib-resistant follicular dendritic-cell sarcoma in a patient-derived orthotopic xenograft nude mouse model. Oncotarget. 2016; 7:33046-33054. doi: 10.18632/ oncotarget.8848.

34. Murakami T, Singh AS, Kiyuna T, Dry SM, Li Y, James AW, Igarashi K, Kawaguchi K, DeLong JC, Zhang Y, Hiroshima Y, Russell T, Eckardt MA, et al. Effective molecular targeting of CDK4/6 and IGF-1R in a rare FUS-ERG fusion CDKN2A-deletion doxorubicin-resistant Ewing's sarcoma patient-derived orthotopic xenograft (PDOX) nude-mouse model. Oncotarget. 2016; 7:47556-47564. doi: 10.18632/ oncotarget.9879.

35. Fu X, Guadagni F, Hoffman RM. A metastatic nudemouse model of human pancreatic cancer constructed orthotopically with histologically intact patient specimens. Proc Natl Acad Sci USA. 1992; 89:5645-5649.

36. Hiroshima $\mathrm{Y}$, Maawy A, Zhang $\mathrm{Y}$, Murakami $\mathrm{T}$, Momiyama M, Mori R, Matsuyama R, Katz MH, Fleming JB, Chishima T, Tanaka K, Ichikawa Y, Endo I, et al. Metastatic recurrence in a pancreatic cancer patient derived orthotopic xenograft (PDOX) nude mouse model is inhibited by neoadjuvant chemotherapy in combination with fluorescence-guided surgery with an anti-CA 19-9-conjugated fluorophore. PLoS One. 2014; 9:e114310. 
37. Hiroshima Y, Zhang Y, Murakami T, Maawy AA, Miwa S, Yamamoto M, Yano S, Sato S, Momiyama M, Mori R, Matsuyama R, Chishima T, Tanaka K, et al. Efficacy of tumor-targeting Salmonella typhimurium A1-R in combination with anti-angiogenesis therapy on a pancreatic cancer patient-derived orthotopic xenograph (PDOX) and cell line mouse models. Oncotarget. 2014; 5:12346-12357. doi: 10.18632/oncotarget.2641.

38. Hiroshima Y, Maawy AA, Katz MH, Fleming JB, Bouvet M, Endo I, Hoffman RM. Selective efficacy of zoledronic acid on metastasis in a patient-derived orthotopic xenograph (PDOX) nude-mouse model of human pancreatic cancer. J Surg Oncol. 2015; 111:311-315.

39. Hoffman RM. Patient-derived orthotopic xenografts: better mimic of metastasis than subcutaneous xenografts. Nat Rev Cancer. 2015; 15:451-452.

40. Blagosklonny MV. Matching targets for selective cancer therapy. Drug Discov Today. 2003; 8:1104-1107.
41. Blagosklonny MV. Teratogens as anti-cancer drugs. Cell Cycle. 2005; 4:1518-1521.

42. Blagosklonny MV. Treatment with inhibitors of caspases, that are substrates of drug transporters, selectively permits chemotherapy-induced apoptosis in multidrug-resistant cells but protects normal cells. Leukemia. 2001; 15: 936-941.

43. Blagosklonny MV. Target for cancer therapy: proliferating cells or stem cells. Leukemia. 2006; 20:385-391.

44. Apontes $\mathrm{P}$, Leontieva OV, Demidenko ZN, Li F, Blagosklonny MV. Exploring long-term protection of normal human fibroblasts and epithelial cells from chemotherapy in cell culture. Oncotarget. 2011; 2:222-233. doi: 10.18632/oncotarget.248.

45. Blagosklonny MV. Tissue-selective therapy of cancer. Br J Cancer. 2003; 89:1147-1151. 